\title{
Putting out the fire: Effects of tastants on oral chemical irritation
}

\author{
DAVID A. STEVENS \\ Clark University, Worcester, Massachusetts \\ and \\ HARRY T. LAWLESS \\ S. C. Johnson \& Son, Inc., Racine, Wisconsin
}

\begin{abstract}
Intense oral irritation, lasting $10 \mathrm{~min}$ or more, was induced by rinses with 1 or $2 \mathrm{ppm}$ capsaicin or with $100 \mathrm{ppm}$ piperine. Subjects judged the perceived irritation after these treatments while periodically rinsing their mouths with solutions of one of four tastants (quinine, sucrose, $\mathrm{NaCl}$, or citric acid), with water, or with nothing (a "no-tastant" condition). The decay of perceived irritation over time was linear for piperine and exponential for capsaicin. The decline in irritation was fastest during trials with citric acid and with sucrose (but more so for sucrose in the capsaicin trials), intermediate for $\mathrm{NaCl}$ and water, and slowest for quinine and the no-tastant condition. Perceived irritation was generally lower while tastant solutions were held in the mouth (relative to irritation rated before sipping them or after expectoration), suggesting an inhibitory effect of oral cooling.
\end{abstract}

Sensations of flavor are mediated by complex input from gustatory, olfactory, and trigeminal systems, which are neuroanatomically distinct and which can be stimulated independently. Information from these three systems combines to form a unitary impression of flavor (Gibson, 1965; Titchener, 1909). To understand how the fused impression of flavor depends, psychophysically, upon various physical stimuli, one must understand the interactions of these systems when they are stimulated simultaneously and under independent control.

The least understood interactions in the realm of flavor have been between the common chemical sense for irritation, mediated by trigeminal input, and the classical gustatory and olfactory senses. In the nasal cavity, mutual inhibition is observed between the modalities of odor and irritation (Cain \& Murphy, 1980). In the oral cavity, partial inhibition of taste sensations by intense oral chemical irritation from pepper-derived compounds has been demonstrated in two studies (Lawless, Rozin, \& Shenker, 1985; Lawless \& Stevens, 1984).

One published study has shown an elevation of thresholds for the irritant capsaicin under conditions of simultaneous stimulation with sucrose (Sizer \& Harris, 1985). However, effects observed at the thresholds of chemical stimulation do not always predict effects above threshold (Bartoshuk, 1978). For example, Rozin, Mark,

Portions of these results were presented at the Seventh Annual Meeting, Association for Chemoreception Sciences, April 27, 1985. The authors thank Jean Magoon for technical assistance. The study was supported by NIH Grant NS 20616.

D. A. Stevens's mailing address is: Department of Psychology, Clark University, Worcester, MA 01610. H. T. Lawless's mailing address is: Product Evaluation, S. C. Johnson \& Son, Inc., Racine, WI 53403. and Schiller (1981) noted little or no elevation of threshold in regular consumers of red pepper, although Lawless et al. (1985) found a pronounced decrement in suprathreshold responsiveness.

No study has investigated the above-threshold effects of gustatory stimulation on chemical irritation in the mouth, although many anecdotes suggest various remedies for pepper burn. Consumers of hot and spicy food often claim that some substances, for example, milk, pineapple, beer, sugar, rice, and unsalted crackers, are effective in reducing the burn sensations from hot pepper.

Capsaicin and piperine, the irritants in red and black pepper, are well suited to studies of interactions between modalities, since they produce little or no taste sensations. That is, they are purely irritative (Lawless, 1984). The purpose of this study was to determine if stimuli from the classical four basic taste categories would alter the burning sensations induced by oral trigeminal irritants. Since the time course of irritation is greatly extended relative to gustatory sensations (10 min or more versus several seconds; Lawless, 1984), a paradigm of repeated gustatory stimulation during the long decay of pepper burn was used, to see if the irritative sensations receded faster or more slowly during stimulation with one tastant than with another. A second question of interest was whether the pattern of interactions would differ between the two irritants.

\section{EXPERIMENT 1}

\footnotetext{
Method

Subjects. Twelve unpaid volunteers, 19 to 39 years of age, served as subjects. Informed consent was obtained, and a questionnaire
} 
on eating habits and body consciousness was administered. Data from this questionnaire are not reported here.

Stimuli. The irritant stimuli were ethanol solutions of capsaicin or piperine diluted in distilled water. The concentrations of irritant were $1 \mathrm{ppm}(1 \mathrm{mg} / \mathrm{liter})$ of capsaicin and $100 \mathrm{ppm}(100 \mathrm{mg} / \mathrm{liter})$ of piperine. The capsaicin stimuli were prepared by dissolving $.04 \mathrm{~g}$ of capsaicin (Sigma Grade 1) in $100 \mathrm{ml}$ ethanol, and mixing $.05 \mathrm{ml}$ of this solution into $20 \mathrm{ml}$ of water immediately before presentation to the subject. The piperine stimuli were similarly prepared by dissolving $.4 \mathrm{~g}$ piperine (Sigma) in $10 \mathrm{ml}$ ethanol, and then adding $.05 \mathrm{ml}$ of this to $20 \mathrm{ml}$ of water.

Four tastants were employed, $.3 \mathrm{M}$ sucrose, $.0056 \mathrm{M}$ citric acid, $.3 \mathrm{M} \mathrm{NaCl}$, and .0001 $\mathrm{M}$ quinine hydrochloride $(\mathrm{QHCl})$, dissolved in distilled water. These concentrations were chosen to produce moderately intense and roughly equal taste sensations. Two additional conditions consisted of (1) water used in place of a tastant and (2) no tastant.

Procedure. The subjects were instructed in the method of magnitude estimation and were allowed to practice by judging the perceived heaviness of four visually identical jars weighing 100,200 , 400 , and $800 \mathrm{~g}$, three times each. They then tasted two $15-\mathrm{ml} \mathrm{sam-}$ ples of $.3 \mathrm{M} \mathrm{NaCl}$ which were assigned a modulus value of 10 . The subjects were instructed to relate their judgments of the perceived intensity of irritation to the sensation magnitude of this modulus.

After rinsing their mouths with distilled water, the subjects swirled $20 \mathrm{ml}$ of either capsaicin or piperine in their mouths for $30 \mathrm{sec}$ and then expectorated. After expectoration, they rated the intensity of the burn relative to the intensity of the $\mathrm{NaCl}$ modulus. Thirty seconds later, and every $30 \mathrm{sec}$ thereafter for $8 \mathrm{~min}$, they sipped $15 \mathrm{ml}$ of one of the tastants, held it in their mouths for $10 \mathrm{sec}$, expectorated, and then rinsed their mouths with water. A minimum of $5 \mathrm{sec}$ elapsed before the next cycle began. The same tastant condition was used throughout the 1630 -sec cycles. In a "no-tastant" condition, subjects used a water rinse in every cycle as if they had sipped a tastant from an empty cup (then rinsed as if they had actually sipped a tastant).

Ratings of perceived irritation were made during three different intervals of each cycle. Ratings made just before the tastant was sipped were called the "Before" interval; those made while the tastant was held in the mouth were called the "During" interval; and those made $2 \mathrm{sec}$ after expectoration were called the "After" interval.

When the 16 cycles of one trial were completed, a 5-min rest ensued to allow any residual oral sensation to dissipate. Two additional 8-min trials were given per day, using new tastants but the same irritant. Each subject thus participated in 4 days of testing. For half the subjects, the trials using capsaicin were given first, followed by piperine; for the others, the order was reversed. The order of tastant conditions within an irritant condition was determined by randomly chosen Latin squares.

Experiment 1 was thus a factorial design with five factors: tastants (6 levels), irritants (2), report intervals (3), cycles of 30-sec time blocks (16), and subjects (12).

\section{Results}

The geometric means of the initial intensity ratings for capsaicin and piperine were 32.6 and 44.4 , respectively, indicating a somewhat stronger "burn" from the piperine treatments. Due to extremely high interindividual variability in ratings of irritation, scores for each irritant were normalized, setting each subject's initial rating of perceived intensity to 100 .

Separate three-way analyses of variance were conducted for the two irritants, with tastant condition, reporting interval (Before, During, and After), and the 16 time cy- cles as factors. For all statistical tests reported below, $\alpha=.01$. For both analyses, there were significant interactions between the time cycle and report interval $[F \mathrm{~s}(30,330)=13.02$ for capsaicin and 6.00 for piperine], indicating different rates of decay for the irritation within the different report intervals. There were also significant interactions between the report intervals and the tastant conditions $[F \mathrm{~s}(10,110)=2.93$ for capsaicin and 7.14 for piperine]. Differences among tastant conditions within each report interval and among report intervals within each tastant condition were tested using Duncan's multiple range tests. These differences are shown in Tables 1 and 2 , and are summarized below.

When capsaicin was the irritant, the perceived "burn" was greater in the Before interval than in the During or After interval, except in the no-tastant condition, in which the three intervals did not differ. This confirmed subjective reports from pilot work, in which subjects remarked that there was an immediate decrement in burn level after sipping. When piperine was the irritant, ratings were highest in the Before interval, lowest in the During interval, and intermediate in the After interval. However, as with capsaicin, no differences in report interval were seen in the no-tastant condition, as might be expected, since nothing was held in the mouth.

In a comparison of the responses across tastant conditions, sucrose and citric acid were lowest, salt, water, and quinine were intermediate, and the no-tastant condition was highest for capsaicin. The pattern was more complex for piperine. Once again, citric acid was generally lowest and not different from sucrose or water. Salt and water were intermediate, but showed some overlap with sucrose (see Table 2). Quinine stood alone among tastants, hav-

Table 1

Mean Perceived Intensities of Capsaicin (1 ppm)

\begin{tabular}{llll}
\hline \multirow{2}{*}{$\begin{array}{c}\text { Tastant } \\
\text { Condition }\end{array}$} & \multicolumn{3}{c}{ Report Interval } \\
\cline { 2 - 4 } & Before & During & After \\
\hline Citric Acid & $24.9^{\mathrm{a}}$ & $18.9^{\mathrm{cg}}$ & $19.3^{\mathrm{eg}}$ \\
Sucrose & $24.9^{\mathrm{a}}$ & $19.4^{\mathrm{ch}}$ & $20.0^{\mathrm{eh}}$ \\
$\mathrm{NaCl}$ & $29.9^{\mathrm{b}}$ & $23.4^{\mathrm{di}}$ & $24.6^{\mathrm{fi}}$ \\
Water & $30.8^{\mathrm{b}}$ & $23.3^{\mathrm{dj}}$ & $24.8^{\mathrm{fj}}$ \\
Quinine & $32.3^{\mathrm{b}}$ & $26.8^{\mathrm{dk}}$ & $26.7^{\mathbf{f k}}$ \\
No Tastant & $36.3^{\mathrm{l}}$ & $36.4^{\mathrm{l}}$ & $36.7^{\mathbf{l}}$ \\
\hline
\end{tabular}

Note: Values within a row or column that do not share a superscript are significantly different (Duncan's multiple range test, $p<.01$ ).

Table 2

Mean Perceived Intensities of Piperine (100 ppm)

\begin{tabular}{|c|c|c|c|}
\hline \multirow{2}{*}{$\begin{array}{c}\text { Tastant } \\
\text { Condition }\end{array}$} & \multicolumn{3}{|c|}{ Report Interval } \\
\hline & Before & During & After \\
\hline Citric Acid & $52.0^{\mathrm{a}}$ & $36.1^{c}$ & $44.1^{e}$ \\
\hline Sucrose & $53.6^{\mathrm{ab}}$ & $41.0^{\text {cd }}$ & $46.8^{\text {ef }}$ \\
\hline $\mathrm{NaCl}$ & $57.8^{\mathrm{b}}$ & $42.0^{\mathrm{d}}$ & $50.1^{f}$ \\
\hline Water & $56.6^{\mathrm{ab}}$ & $38.5^{\mathrm{cd}}$ & $47.1^{\text {ef }}$ \\
\hline Quinine & 65.1 & 50.0 & 58.9 \\
\hline No Tastant & $74.4^{8}$ & $75.1^{8}$ & $75.2^{\mathrm{g}}$ \\
\hline
\end{tabular}

Note: Values within a row or column that do not share a superscript are significantly different (Duncan's multiple range test, $p<.01$ ). 


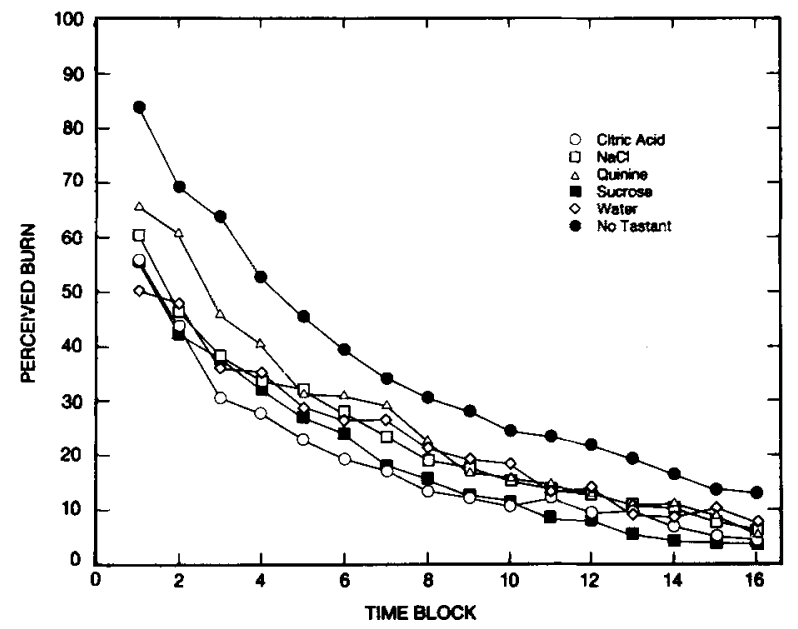

Figure 1. Mean perceived oral irritation as a function of time, for the six tastant conditions, in the During report interval, for $1 \mathrm{ppm}$ capsaicin.

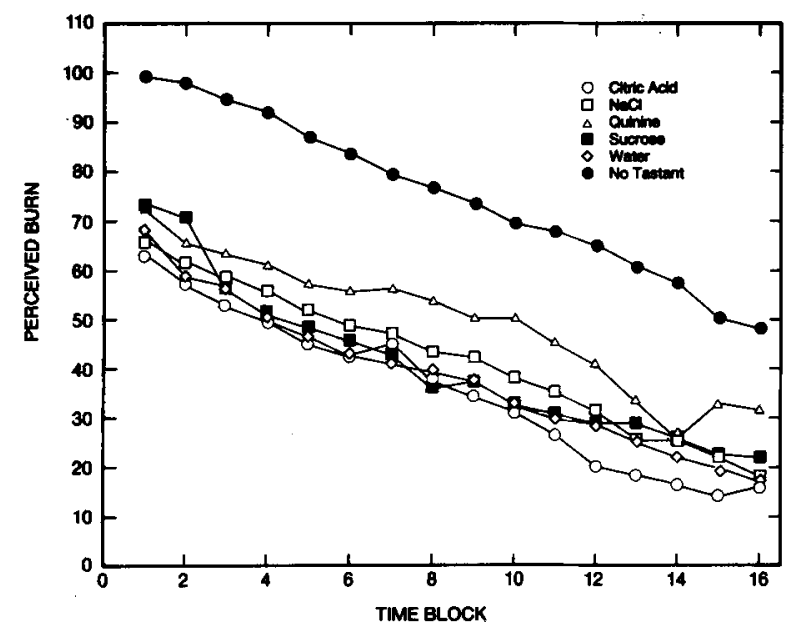

Figure 2. Mean perceived oral irritation as a function of time, for the six tastant conditions, in the During report interval, for 100 ppm piperine.

ing significantly higher reports of irritation. Once again, the no-tastant condition was highest of all.

The pattern of decrement in irritation over time is shown in Figure 1 for capsaicin and in Figure 2 for piperine, for the During report interval. The decline in intensity generally followed a linear function for piperine and a negatively accelerated one for capsaicin. This was confirmed by fitting equations for exponential decay to the capsaicin data (see Lawless, 1984). For capsaicin, statistically larger correlations were found for the exponential fit (as opposed to linear) in 17 of 18 conditions (median $r^{2}=.981$, fit to group means). For piperine, no improvement was seen in the exponential fit (median $r^{2}$ for linear fit $=.973$ ).

\section{EXPERIMENT 2}

From the results of Experiment 1, it was unclear whether the pattern of observed differences between the irritants was due to the inequality of capsaicin and piperine in initial burn level or to intrinsic qualitative differences between the irritants. Therefore, a second experiment was carried out with a higher level of capsaicin, better equated to the initial level of irritation observed for piperine in Experiment 1.

\section{Method}

Twenty-four unpaid volunteers served as subjects. A capsaicin solution was prepared in the same manner as the capsaicin in Experiment 1 , except that the final concentration was doubled to $2 \mathrm{ppm}$ ( $2 \mathrm{mg} / \mathrm{liter}$ ). The same procedure as Experiment 1 was used, except that this single irritant was given.

\section{Results}

The geometric mean of initial intensity (raw data) was 45.9 , a better match to the value of 44.4 observed for piperine in Experiment 1. As before, the scores were normalized for further analyses by setting the initial intensity of irritation to 100 . All statistical tests were conducted with $\alpha=.01$.

A three-way analysis of variance was performed on the normalized scores. There was a significant interaction of time cycle and report interval $[F(30,690)=15.95]$ and an interaction of report interval and tastant condition $[F(10,230)=4.20]$. Cell means and paired comparisons by Duncan's tests are shown in Table 3 .

Comparisons of the intensity of burn among report intervals showed that for sucrose, salt, and citric acid, the burn was lower in the During and After intervals than in the Before interval. For water, it was also lower in the During than in the Before interval. For quinine and the no-tastant conditions, no differences were seen as a function of time of rating.

Comparisons of the intensity of burn among tastant conditions once again showed the no-tastant and quinine conditions to be significantly higher than the other tastants. Sucrose was significantly lower than any other condition in the During interval. It overlapped with water in the After interval, but was still lower than the salt and citric acid conditions.

Table 3

Mean Perceived Intensities of Capsaicin (2 ppm)

\begin{tabular}{llll}
\hline \multirow{2}{*}{$\begin{array}{c}\text { Tastant } \\
\text { Condition }\end{array}$} & Before & During & After \\
\cline { 3 - 4 } Citric Acid & $25.8^{\mathrm{a}}$ & $20.7^{\mathrm{ch}}$ & $21.6^{\mathrm{ch}}$ \\
Sucrose & $23.1^{\mathrm{a}}$ & $13.7^{\mathrm{i}}$ & $16.3^{\mathrm{fi}}$ \\
$\mathrm{NaCl}$ & $24.7^{\mathrm{a}}$ & $19.6^{\mathrm{cj}}$ & $21.0^{\mathrm{ej}}$ \\
Water & $23.6^{\mathrm{ak}}$ & $18.4^{\mathrm{cfl}}$ & $19.4^{\mathrm{eflk}}$ \\
Quinine & $31.7^{\mathrm{bm}}$ & $34.1^{\mathrm{dm}}$ & $32.0^{\mathrm{gm}}$ \\
No Tastant & $32.9^{\mathrm{bn}}$ & $33.5^{\mathrm{dn}}$ & $33.4^{\mathrm{gn}}$ \\
\hline
\end{tabular}

Note: Values within a row or column that do not share a superscript are significantly different (Duncan's multiple range test, $p<.01$ ). 


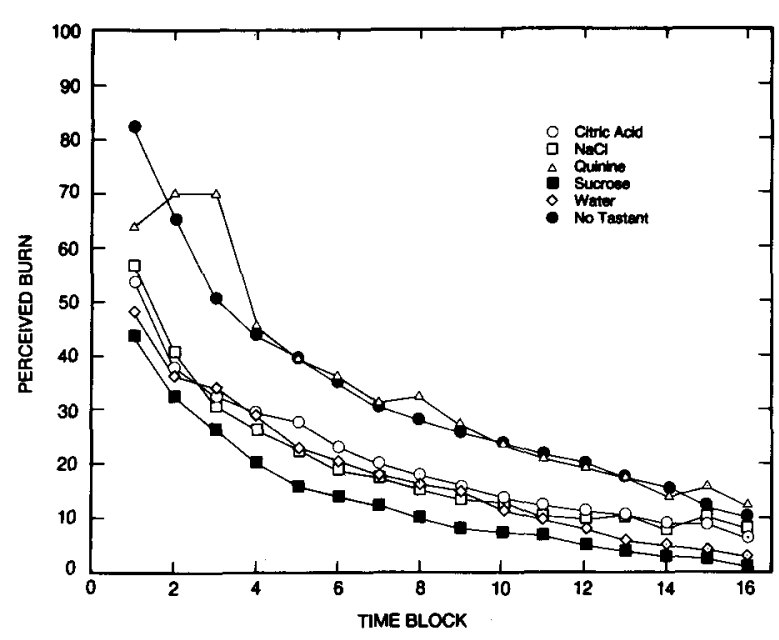

Figure 3. Mean perceived oral irritation as a function of time, for the six tastant conditions, in the During report interval, for 2 ppm capsaicin.

Figure 3 shows the pattern of decrement in irritation over time for the During interval. As in Experiment 1, the function for capsaicin appears to be negatively accelerated. This was confirmed by a statistically better fit of exponential decay, as opposed to linear, in 15 of 18 curves (median $r^{2}=.986$, fit to group means).

\section{Discussion}

Govindarajan (1979), in a comprehensive review of irritant compounds, suggested that all pungencies (his term for oral irritants) are qualitatively the same. Although this may or may not be true in terms of perceived quality of burn, a growing number of observations indicate important sensory differences among oral irritants. Previous research has shown differences in the spatial pattern of stimulation in the mouth (Lawless, 1984) and different degrees of inhibition of taste sensations (Lawless \& Stevens, 1984).

Two new areas of difference are documented by the present study. First, during taste stimulation, capsaicin shows a pattern of exponential decay, whereas piperine shows a linear one. Second, although the irritation from piperine was attenuated most effectively by citric acid, capsaicin was also affected strongly by sucrose. This last result corroborates the partially inhibitory effects of sucrose on capsaicin at threshold noted by Sizer and Harris (1985).

After we undertook this study, two reports have appeared which indicate an attenuation of capsaicin burn by oral cooling (Sizer \& Harris, 1985; Green, in press). In our study, irritation was rated as less intense, in general, when solutions were held in the mouth (the During condition) than before sipping or after expectoration. Since room-temperature solutions were used $\left(22^{\circ} \mathrm{C}\right.$ vs. about $36^{\circ} \mathrm{C}$ for mouth temperature), this could reflect an inhibition of irritation by oral cooling. However, cooling cannot explain all of the decrements. Since some solutions were more or less effective than water (a coolant but not a tastant), the notion that the role of a tastant was merely one of cooling can be rejected.

This raises the possibility that the relative failure of quinine to reduce the burn represents an enhancement, superimposed upon an inhibitory cooling effect. To examine this possibility, future interaction studies should systematically vary temperature and tastant. A second explanation for the relative inefficacy of quinine in reducing the burn is that subjects failed to differentiate between irritation and bitterness, because of the negative hedonic character they have in common. However, citric acid also has a hedonically negative sour taste. If subjects were simply responding to the hedonically negative character, citric acid should also have shown slower decay. Instead, it was one of the most effective tastants in decreasing the irritation.

It is possible that the relative failure of quinine to decrease the burn is due to an intrinsic trigeminal or irritative component of quinine. Overlapping neural mechanisms for bitterness and irritation are plausible for several reasons. First, the glossopharyngeal nerve innervates the circumvallate papillae and responds vigorously to bitter substances (Collings, 1974). The glossopharyngeal nerve also contains substance $P$, a neurotransmitter for pain which is depleted by capsaicin injection, causing desensitization (Nagy, Goedert, Hunt, \& Bond, 1982; Silver, Mason, Marshall, \& Maruniak, 1985; Yamasaki, Kubota, \& Tohyama, 1985). Second, rats injected with capsaicin are less responsive to quinine in drinking water (Silver et al., 1985). Third, intense stimulation with capsaicin or other red-pepper compounds leads to decreased perception of quinine in human psychophysical studies (Lawless et al., 1985; Lawless \& Stevens, 1984). Finally, Okuni (1977) observed similar across-fiber patterns in response to capsaicin and to quinine in the chorda tympani.

\section{REFERENCES}

Bartoshuk, L. M. (1978). The psychophysics of taste. American Journal of Clinical Nutrition, 31, 1068-1077.

CaIN, W. S., MurPHY, C. L. (1980). Interaction between chemoreceptive modalities of odor and irritation. Nature, 284, 255-257.

Collings, V. B. (1974). Human taste response as a function of locus of stimulation on the tongue and soft palate. Perception \& Psychophysics, 16, 169-174.

GiBson, J. J. (1965). The senses considered as perceptual systems. Boston: Houghton-Mifflin.

Govindarajan, V. S. (1979). Pungency: The stimuli and their evaluation. In J. C. Boudreau (Ed.), Food taste chemistry (ACS Symposium Series 115). Washington, DC: American Chemical Society.

GreEN, B. G. (in press). Sensory interactions between capsaicin and temperature in the oral cavity. Chemical Senses.

Lawless, H. (1984). Oral chemical irritation: Psychophysical properties. Chemical Senses, 9, 143-155.

Lawless, H., Rozin, P., \& Shenker, J. (1985). Effects of oral capsaicin on gustatory, olfactory and irritant sensations and flavor identification in humans who regularly or rarely consume chili pepper. Chemical Senses, 10, 579-589.

LAWLESS, H. T., \& Stevens, D. A. (1984). Effects of oral chemical irritation on taste. Physiology \& Behavior, 32, 995-998. 
Nagy, J. I., Goedert, M., Hunt, S. P., \& Bond, A. (1982). The nature of the substance P-containing nerve fibers in the taste papillae of the rat tongue. Neuroscience, 7, 3137-3151.

OKUN1, Y. (1977). Responses of the chorda tympani fibers of the rat tongue to pungent spices and irritants in pungent spices. Shika Gahuko, 77, 1323-1349

Rozin, P., Mark, M., \& Schiller, D. (1981). The role of desensitization to capsaicin in chili pepper ingestion and preference. Chemical Senses, 6, 23-31.

Silver, W. L., Mason, J. R., Marshall, D. A., \& Maruniak, J. A. (1985). Rat trigeminal, olfactory, and taste responses after capsaicin desensitization. Brain Research, 333, 45-54.
Sizer, F., \& Harrus, N. (1985). The influence of common food additives and temperature on threshold perception of capsaicin. Chemical Senses, 10, 279-286.

TITCHENER, E. B. (1909). A text-book of psychology. New York: Macmillan.

Yamasaki, H., Kubota, Y., \& Tohyama, M. (1985). Ontogeny of substance P-containing fibers in the taste buds and the surrounding epithelium. Developmental Brain Research, 18, 301-305.

(Manuscript received January 27, 1986; accepted for publication April 2, 1986.) 